\title{
EDITORIAL
}

\section{A welcome from our new editors: change and continuity in politics and gender}

\author{
Jessica Fortin-Rittberger, jessica.fortin-rittberger@sbg.ac.at \\ University of Salzburg, Austria \\ KhursheedWadia, Khursheed.Wadia@warwick.ac.uk \\ University of Warwick, UK \\ PhillipAyoub,payoub@oxy.edu \\ Occidental College, USA \\ Althea-Maria Rivas,ar66@soas.ac.uk \\ School of Oriental and African Studies (University of London), UK \\ Emily St Denny, ed@ifs.ku.dk \\ University of Copenhagen, Denmark
}

Key words politics $\bullet$ gender $\bullet$ political science $\bullet$ sexuality $\bullet$ intersectionality

To cite this article: Fortin-Rittberger, J., Wadia, K., Ayoub, P., Rivas, A. and St Denny, E. (2021) A welcome from our new editors: change and continuity in politics and gender, European Journal of Politics and Gender, vol xx, no xx, 1-3,

DOI: $10.1332 / 251510820 X 16067427021442$

We are delighted to introduce ourselves as the new editorial team for EJPG and are excited to be leading the production of this first issue since we took up post. Of course, we would not be here if it had not been for the journal's amazing founders and outgoing editors, Petra Ahrens, Karen Celis, Sarah Childs, Isabelle Engeli, Elizabeth Evans and Liza Mügge. This outstanding group of scholars saw the need for a journal dedicated to advancing innovative research on gender and politics and took on the enormous challenge of creating the journal and its vision from scratch. Thanks to their pioneering effort, we are in the privileged position of inheriting a young, vibrant and already successful journal.

We would obviously also not be here without the brilliant EJPG community that grew out of the European Conference on Politics and Gender (ECPG) and has gone from strength to strength. The ECPG has brought together and provided a sense of community for different generations of politics and gender scholars around the world. EJPG benefits from the vast pool of knowledge, expertise and experience residing in this community. Without this diverse and vibrant community, which is reflected in our editorial board, authors, reviewers and readers, none of this would exist. 
At the heart of its mission, EJPG endeavours to make gender, intersectionality and sexuality central to understanding politics. 'Because politics is about power, and power is gendered' (Ahrens et al, 2018: 6). As we face an increasing backlash against values and norms pertaining to the equality of gender and sexuality, we believe the journal's mission to be even more relevant today than at the time of its inception.

In that spirit, the journal must continue to develop as an inclusive space for research on the gendered nature of politics, as practice and discourse, with a broad understanding of gender and deepening recognition of intersectional realities as gender intersects with other identities, including those around race, class and ability. It will also promote a holistic understanding of gender that includes sexuality and gender identity, as per our mission. In doing so, we want to acknowledge the limited space the field has made for work on LGBTQI politics, as well as the persistent stigma assigned to it in the discipline. The journal seeks to span geographical boundaries, welcoming scholars and scholarship from around the world, particularly from underrepresented countries in the Global South and East and Central Europe. The journal must continue to place value on and attract methodological diversity, and make leaps in areas where it has so far taken smaller steps: international relations and political theory, to name but two. Finally, the journal should be able to speak to and provide mentorship to early-career researchers and those who have left their homes in parts of the world where political freedoms and human well-being are under threat.

The following are the goals we are setting ourselves for our tenure. First, we will seek to increase both high-quality and diverse submissions to EJPG, particularly in new and emerging areas of interest to gender and politics scholars. Maintaining high scholarly standards is the key - the better the content published, the more and the better the content submitted. We will pay particular attention to encouraging leading gender and politics scholars from under-represented regions in Europe and the Global South to submit their work to EJPG.

Our second, and related, objective will be to increase the geographic diversification of submissions to EJPG and ensure that the editorial board is representative of the diverse nature of our field, for instance, through encouraging institutional subscriptions in countries where EJPG is not so well known. Third, we will focus on author satisfaction by striving to offer a rapid turnaround from initial submission to acceptance or rejection of papers, maintaining good communication with our authors and limiting revise and resubmit rounds.

Fourth, we will endeavour to extend the readership and impact of articles published in EJPG by harnessing the strength of social media to promote articles upon publication. We will encourage article submissions from research teams collaborating across multiple cultures and/or countries. Ultimately, we are committed to ensuring that EJPG secures a Web of Science ESCI ranking.

We believe our team is particularly well suited to the task of supporting scientific research on women and politics, intersectionality, sexuality, and gender identity. We have assembled a team with wide-ranging interests and a pluralistic skill set covering specialisms in political theory, comparative politics, the politics of development, public policy and methodology. We are looking forward to working with our global community of gender in politics scholars. Our main task as the new editorial team will be to attract and select the best papers, and to highlight the most recent advances in the field, all with the ultimate aim of increasing the readership, distribution and presence of the journal. 
Successful projects are built through collaborations based on curiosity, creativity and sheer hard work, as well as through trust, respect and generosity. To this end, we invite you, dear EJPG community, to join us in the next stage of the journal's journey by: sending us your best writing; encouraging submissions from your colleagues and friends around the world; accepting our invitations to review papers; putting EJPG on your and your students' reading lists; entering our annual special issue and best article competitions; and hollering how much you love EJPG, whether through Twitter, Instagram, Facebook or elsewhere. Let us do this together. Let us make political science better and reflective of all its community.

\section{Conflict of interest}

The authors declare that there is no conflict of interest.

\section{References}

Ahrens, P., Celis, K., Childs, S., Engeli, I., Evans, E. and Mugge, L. (2018) Politics and gender: rocking political science and creating new horizons, European Journal of Politics and Gender, 1(1-2): 3-16. 